\title{
Neurological Screening
}

National Cancer Institute

\section{Source}

National Cancer Institute. Neurological Screening. NCI Thesaurus. Code C89339.

A specific type of neurologic examination for early detection of disease(s) and/or disorder(s). 